\title{
EL CONCEPTO DE CIUDADANÍA EN ETIENNE BALIBAR Y LA NUEVA ESTRATEGIA ZAPATISTA. RESPUESTAS A LA GOBERNANZA
}

\author{
The Concept of Citizenship in Etienne Balibar and the New Zapatista Strategy. \\ Responses to Governance
}

Hero Suárez Ruiz

\author{
Ecole Supérieure de Sciences Economiques et Commerciales ESSEC \\ herosuarez@gmail.com
}

\begin{abstract}
Resumen:
El artículo analiza la categoría de ciudadanía en la filosofía de Etienne Balibar y la compara con los postulados del movimiento neozapatista. Para el filósofo galo dicha noción se complementa con la de sujeto y contiene una fuerza emancipadora y transformadora, en la medida en que hace alusión al proceso por el cual adquieren derechos los sujetos de y a la política. Pensada en la tensión que genera, la categoría aparece como una práctica que daría cuenta de las acciones colectivas destinadas a incluir a los excluidos en «el derecho a tener derechos», elementos que serán identificados en la estrategia y articulación del movimiento político chiapaneco.
\end{abstract}

\section{Palabras clave:}

Balibar, neozapatismo, ciudadanía, sujeto, praxis, emancipación, transformación.

\begin{abstract}
:
The article analyses the category of citizenship in the philosophy of Etienne Balibar and relates it to the Neo-Zapatista movement of Chiapas. For the French philosopher, this notion is complemented by that of subject, while containing an emancipating and transforming force, as it refers to the process by which the subjects, subjects of politics and subjects to politics acquire rights. When thinking of its inherent tension, the category appears as a practice that would account for collective actions designed to include the excluded regarding "the right to have rights", as the Zapatistas have done.
\end{abstract}

\section{Keywords:}

Balibar, Neo-Zapatista movement, Citizenship, Subject, Emancipating, Transforming. 


\section{INTRODUCCIÓN}

A finales de los años ochenta y a lo largo de la década de los noventa del siglo pasado, el concepto de ciudadanía reapareció con fuerza dentro del debate teórico. Esta recuperación se suele pensar como una de las respuestas a la hegemonía neoliberal, la cual emplazó primero la gestión y después la gobernanza en el centro del paradigma de gobierno, aboliendo con ello las fronteras epistemológicas entre la gestión de las empresas y los principios del gobierno público. En líneas generales, las teorías políticas de carácter conservador dentro del liberalismo tomaron la vía según la cual el concepto de ciudadanía debía ser abandonado o simplemente relegado a segundo plano, de tal manera que la sociedad civil con pocos derechos y menos obligaciones pudiese, libre de las interferencias del Estado, autogestionarse siguiendo el modelo de las empresas privadas.

Frente al emplazamiento de las técnicas del management como patrón para evaluar las acciones de gobierno de lo público y la despolitización de los individuos que ello conlleva, desde posturas progresistas se comenzó a explorar el concepto como un posible sustituto del de "clase social», "pueblo»u otros a la hora de articular mayorías sociales dispuestas a participar en la política. En este contexto, Étienne Balibar explora la noción de ciudadanía y la defiende como capaz de justificar acciones destinadas a crear mundos comunes e inclusivos ${ }^{1}$. Estudia la categoría desde las tensiones que ella plantea entre la libertad y la igualdad, la autonomía de la política y la institucionalidad, el reconocimiento y la identidad, el poder constituido y el insurreccional, las fronteras y el nomadismo, y resuelve que estas tensiones propias a la categoría pueden servir para democratizar la democracia. Defiende la inclusión dinámica de cada vez más individuos que se encuentran en los márgenes de nuestras sociedades actuales dentro de una categoría que abre la puerta al derecho a tener derechos ${ }^{2}$. Derecho a tener derechos que garantiza el reconocimiento y la participación de un cada vez mayor número de individuos en la política, y por ende en la creación de mundos comunes.

En la actualidad, debido al aumento de las desigualdades ${ }^{3}$, al auge de los populismos de derecha en los países occidentales y sus formas de racismo institucional, se está excluyendo a cada vez más individuos de la posibilidad de disfrutar del estatus garantizado por el concepto de ciudadanía. En este sentido, queremos presentar la propuesta de Balibar como una forma de pensar otra senda

\footnotetext{
${ }^{1}$ Las reflexiones de Etienne Balibar sobre el concepto de ciudadanía se extienden a lo largo de tres décadas y continúa profundizando en ellas a día de hoy.

${ }^{2}$ Las nociones de «acción» y de «derecho a tener derechos» Balibar los utiliza en el sentido que les da Hannah Arendt.

${ }^{3}$ En Informe Mundial sobre Ciencias Sociales 2016 de la UNESCO, titulado Afrontar el reto de las desigualdades y trazar vías hacia un mundo justo, se demuestra que el $1 \%$ de la población posee casi la mitad de la riqueza de los hogares y que los 62 individuos más ricos del planeta tienen tanta riqueza como la mitad de la población mundial. Consultado el 3 de febrero de 2017, http://www.unesco.org/new/es/media-services/single-view/news/unchecked_inequalities_could_threaten_uns_sustainable_dev/
} 
por la que marchar. A nuestro modo de entender, ésta permite pensar rumbos marcados por las ansias de democratizar las democracias actuales. Democratización que nunca será total, pero que servirá de guía a la hora de justificar políticas incluyentes que amplían las libertades y garantizan una cada vez mayor igualdad.

En esta línea, el presente texto se ocupa de la categoría y de las tensiones que Balibar señala, para terminar confrontando su propuesta con el ejemplo del movimiento neozapatista ${ }^{4}$, el cual aparece en el mismo momento en el que Balibar forja y explora su concepción del ciudadano-sujeto y que se enfrenta con la misma situación a la que se refiere el filósofo, aunque desde la práctica. Este ejemplo nos parece que da cuenta de ciertos de rasgos que pueden servirnos para pensar una forma de ejercer la ciudadanía inclusiva y participativa próxima, aunque no idéntica, a la del autor galo, en cuanto ambas toman en consideración a los agentes subalternos y los sitúan en el centro de las reflexiones. Agentes subalternos que alumbran nuevos dominios sobre los que hacer girar las acciones ciudadanas. Acciones que tanto en la teoría de Balibar como en la praxis neozapastista pretenden reorientar el mundo y hacer de la política una actividad mediante la cual se puedan construir mundos en los que quepan muchos mundos.

\section{DESPUÉS DEL SUJETO}

Uno de los textos claves para comprender el desarrollo de la noción de ciudadanía en el pensamiento de Balibar es "Réponse à la question de Jean-Luc Nancy: "Qui vient après le sujet?"» (Balibar, 2011: 35-65). Como se observa, el texto es la respuesta a la pregunta que sirve de apertura para una revista estadounidense dedicada a la filosofía en Francia, en un momento en el que se ha vuelto a declarar la muerte del sujeto. Nancy plantea la pregunta de la siguiente manera:

La crítica o la deconstrucción de la subjetividad ha sido uno de los grandes motivos del trabajo filosófico en Francia. Tal movimiento se apoya sobre los conocimientos de Marx, Nietzsche, Freud, Husserl, Heidegger, Bataille, Wittgenstein, así como de los de la lingüística, las ciencias sociales, etc. Aunque también proviene, de manera consustancial, de la experiencia práctica, ética y política de la Europa de los años 30: los fascismos, el estalinismo, la guerra, los lagers, la descolonización y el nacimiento de nuevas naciones; la dificultad de orientarse entre una identidad «espiritual devastada» y el «economicismo americano», entre la pérdida de sentido y la acumulación de signos: tantas instancias de interrogación sobre las diversas funciones del sujeto (Nancy, 1989: 7).

Por lo que a partir de ahí plantea la cuestión: Quién viene después del sujeto, a la que Balibar responde: "después del sujeto viene el ciudadano» y le añade: el «ciudadano como sujeto». Hará aparecer a la categoría de ciudadanía como aquella que puede reemplazar a otras denostadas por las experiencias colectivas del siglo XX y la definirá como central a la hora pensar acciones políticas destinadas a la

\footnotetext{
${ }^{4}$ En el presente texto nos referiremos al movimiento insurgente chipaneco surgido en 1994 como «neozapatista» para diferenciarlo del movimiento originario propio de la Revolución Mexicana.
} 
profundización democrática. Defenderá la categoría para hacer frente a la visión liberal que insta a los individuos a buscar sus propios intereses en el plano de la sociedad civil. Visión ésta última que se ha vuelto hegemónica y que genera el repliegue de los individuos de la esfera política a la esfera mercantil.

Para argumentar su respuesta se remite a la etimología latina del concepto de sujeto, según la cual éste deriva, por un lado, del término neutro subiectum, que

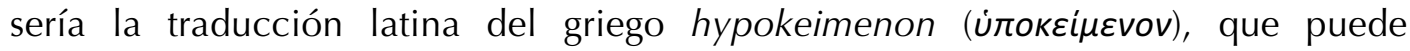
traducirse como "sustrato», "sustancia», así como por la acepción que le interesa a Balibar, a saber, como "sujeto», pero en el sentido más habitual en español: como sujeto de un enunciado, sujeto de la enunciación, como el actor de un acto. Mientras que por otro, del masculino subiectus, del que proviene el término del latín medieval subditus que, como resulta obvio, da «súbdito» en castellano (Balibar, 2011: 67). Esta doble huella significativa resulta totalmente clara en la lengua francesa, en cuanto el término francés sujet conserva esa doble significación. En francés significa tanto «sujet du roi» que se traduce literalmente por «súbdito del rey», como "sujet grammatical», a saber, «sujeto gramatical» y que dentro del constitucionalismo francés se traduce también por «sujet de droit» que sería «sujeto de derechos»; y es a partir de las múltiples acepciones del término (subiectus / subditus) desde la que responde que quien viene después del sujeto es el ciudadano; a saber, después del súbdito del Antiguo Régimen, tras la Revolución Francesa y la Declaración de los Derechos del Hombre y del Ciudadano, quien aparece es el ciudadano.

Balibar interpreta la Declaración de 1789, en concreto, el primer artículo de la misma, -a saber, "Todos Los hombres nacen y permanecen libres e iguales en derechos. Las distinciones sociales sólo pueden fundarse en la utilidad común»-, para a partir del poder performativo del mismo -en el que se lee e instituye la igualdad entre los hombres- defender que tras el sujeto como subiectus aparece el ciudadano, en cuanto el artículo supone -en términos de posibilidad- el fin de los privilegios y un nuevo sentido para la igualdad fundamentado en derechos (Balibar, 2011: 52). En sus propias palabras: «He aquí la respuesta: Después del sujeto viene el ciudadano. El ciudadano (definido por sus derechos y sus deberes) es ese "no sujeto" que viene después del "sujeto" [súbdito] y cuya constitución y reconocimiento ponen fin (en principio) a la subordinación [l'assujettissement] del sujeto» (Balibar, 2011: 43).

Para Balibar, la Revolución Francesa y la Declaración son los momentos que instituyen la ciudadanía moderna, son la ruptura que permite que los hombres no nazcan como súbditos sino como sujetos libres e iguales. Estos eventos le imprimen a la ciudadanía un nuevo sentido, cuyo potencial igualador en términos de libertades la dota de una fuerza emancipadora y transformadora; aunque no por ello el término se libra del subiectus, es decir, el ciudadano continuará teniendo una vinculación a la obediencia, continuará sujeto a algo.

En este sentido, se puede afirmar que retoma la doble noción de sujeto que Althusser establece en su célebre texto «Ideología y Aparatos Ideológicos de Estado». Según la distinción de este último, el sujeto en términos de uso puede ser pensado como libre y responsable de sus actos o como un sujeto-sujetado, como el 
sujeto sujeto a poderes diversos. En sus propias palabras: «En la acepción corriente del término, "sujeto" significa de hecho: 1) una subjetividad libre: un centro de iniciativa, autor y responsables de sus actos; y 2) un ser subordinado, sumiso a una autoridad superior, por lo tanto, despojado de su libertad, salvo la de aceptar libremente la sumisión» (Althusser, 1979: 134).

Ahora bien, para Althusser no habrá ningún sujeto más allá del ideológico, esto es, el único sujeto será el segundo, el del de la sujeción que se cree libre. Ese sujeto se irá constituyendo en su contacto con la ideología. No surge por sí mismo ni aparece en todos los casos, sino que emerge cuando la ideología lo interpela. El sujeto, por tanto, no será el sujeto constituyente y preexistente propio de la filosofía cartesiana, sino que estará constituido por la ideología, de ahí que ese sujeto supuestamente libre no juegue el papel que él cree sino aquél que se le ha asignado. El segundo es el que crea al primero: el sujeto solo no es libre pero cree serlo debido a la ideología.

Como sugiere Daniel Bensaïd, Althusser trata de obviar el concepto de sujeto y sustituirlo por el concepto de proceso. Con ello lo que pretende subrayar el hecho de que todo discurso produce un efecto de subjetividad, y son los discursos los que hacen emerger al sujeto como un simple efecto. El sujeto así pensado no sería el agente del mismo, sino el paciente, dicho con otras palabras, el sujeto sería performado a partir de la ideología, serán los discursos los que producen a los sujetos y no los sujetos los discursos ${ }^{5}$.

Para Balibar, sin embargo, ambos aspectos del sujeto son indispensables y no se debe excluir a ninguno para pensar las acciones políticas capaces de promover la emancipación de los sujetos y transformación de las condiciones políticoeconómicas (Balibar, 1997: 17-53). De ahí que deje de lado, en un primer momento, la interpelación del individuo en sujeto y comience por centrarse en la interpelación del sujeto como individuo. Se focaliza, siguiendo a Michel Foucault, en la manera en la que los individuos son subjetivados. Por lo que su interés se centra en los mecanismos de subjetivación que les atribuye responsabilidades propias a ellos mismos en la conformación del Estado moderno, como pueden ser las responsabilidades penales, morales, raciales, sexuales, nacionales $u$ otras.

A su juicio, este tipo de subjetivación propia de la ciudadanía -que Foucault identificó en su en procesos de formación de los Estados modernos- genera tensión

\footnotetext{
${ }^{5}$ Lo que Bensaïd ejemplifica con la siguiente metáfora: «A diferencia del arquitecto que en un principio tiene la casa que va a construir en su cabeza, el topo no sigue un plan preconcebido. Como la colmena de la abeja, la topera toma forma a medida que se construye. Cavando su laberinto de galerías, de cruces de caminos, de bifurcaciones propicias a la sorpresa de un encuentro, el topo descubre su propia vocación. La visión que da Bensaïd de Althusser plantea el hecho de que el sujeto se constituye, para este último, mediante la ideología, de ahí que no pueda ser considerado como un sujeto soberano que se auto-constituye a sí mismo. A su vez, será un actor de la historia, en cuanto la historia, como la topera que no depende del topo: es «un proceso sin sujeto», y el topo, así como lo que se piensa como sujeto, no es sino una construcción de los «Aparatos Ideológicos del Estado» (Bensaïd, 2007).
} 
cuando se intensifican las contradicciones inherentes a las diferencias y esas contradicciones aparecen de manera recurrente, además de en otros lugares, en el contexto creado por la vigencia del artículo mencionado de la Declaración. Las tensiones en las formas de subjetivación se producen por el incumplimiento de la igualdad que enuncia el artículo. La falta de lo que Balibar denomina igualibertad (l'égaliberté)- que se resume en el hecho de que la libertad no pueda aparecer sin igualdad ni a la inversa- provoca una forma de subjetividad insurreccional que puede ser pensada como constituyente (Balibar, 2011: 62). De esta manera, un individuo se diferenciaría de los otros cuando por una cuestión de índole social no pueda disfrutar de las condiciones de igualdad y, por tanto, de libertad declaradas por el artículo ${ }^{6}$.

En este sentido, como señalamos anteriormente, a pesar de que el ciudadano remplace al súbdito tras la Revolución y la Declaración, el sujeto (como súbdito) no desaparece del todo, sino que acompaña al ciudadano, en la medida en que éste continuará estando sujeto al derecho -en tanto que sujet du droit-, al tiempo que sujeto a sus diferencias, condiciones, deseos, pulsiones, etc. En fin de cuentas, los ciudadanos y ciudadanas estarán sujetos a sus identidades. Por ello, para él se debe hablar en lugar de identidades, siguiendo a Althusser, de procesos de identificación, en cuanto entiende que las identidades no están establecidas de una vez por todas, sino que más bien la identidad o, mejor dicho, los procesos de identificación deben ser pensados como procesos inacabados. En esta línea, defiende la idea de que estos procesos generan un imaginario que no puede ser ni puramente individual ni exclusivamente colectivo, sino transindividual (Balibar, 1997: 353-369).

Esto lo explica aludiendo a que, por un lado, el «sí mismo» no puede nunca reducirse a ningún modelo elegido o impuesto, sino que se tiene que vincular a un sistema que gire en torno a las relaciones sociales reales y simbólicas. Al tiempo que, por otro, la identidad colectiva debe considerarse como la pertenencia del individuo a un "nos-otros», -tanto en el sentido de que el individuo pertenece al grupo como que la colectividad le pertenece-; lo que por otra parte no puede suponer la constitución de un vínculo en la realidad entre los imaginarios individuales. Resultaría absurdo suponer que se comparten de manera idéntica tales imaginarios entre otras cosas porque las identidades son ambiguas, ningún individuo puede contar con una única y exclusiva identidad, sino que más bien las diferentes identidades deben pensarse como solapadas las unas sobre las otras en un mismo sujeto individual (Balibar, 1997: 45-47).

La transindividualidad garantiza la igualdad en la diferencia y permite pensar la universalidad en forma de aporía. La universalidad de derechos fundados en la igualdad de seres diferentes por los procesos de identificación, pero iguales en tanto que libres. Se trata de pensar una libertad fundada sobre la igualdad y engendrada por el movimiento de igualdad, que será «ilimitada o, más exactamente, autoilimitada, en cuanto no tendrá más límites que aquellos que ella se asigna a sí

\footnotetext{
${ }^{6}$ A este respecto, uno de los casos que más interesa a Balibar es el de los sin papeles y entiende que su lucha es una lucha ciudadana por el derecho a tener derechos.
} 
misma, límites que vendrán del hecho de poder respetar la regla de la igualdad» (Balibar, 2011: 52).

Balibar arremete contra la visión de la ciudadanía como un mero estatus, en cuanto para él, al igual que para Jacques Rancière, la ciudadanía es sobre todo una «acción» en el sentido que le da Arendt: es una recreación de la vida dentro de la pluralidad que le permite al hombre conocerse en su diferencia con los otros y pertenecer a la comunidad humana, aunque también en el sentido de hacerse escuchar y desde la acción colectiva perseguir la consecución de derechos. El ciudadano, para ellos, no tendrá un estatus fijo alcanzado de manera pasiva. Tampoco estará ligado a un grupo identitario preexistente en la sociedad. Son sus «acciones» las que darán contenido a la ciudadanía.

Al contrario, pensar la ciudadanía como un estatus, como hacen según Balibar, politólogos y juristas, implicaría pensarla como la simple nacionalidad, como si el ciudadano o la ciudadana fuesen meros sujetos pacientes. Supondría concebir la ciudadanía como algo pasivo y por tanto como sujeto-sujetado a una identidad estable. Lo que resulta contradictorio con los procesos constituyentes constantes desde los que él entiende que se construyen las identidades transindividuales. Esto supone el olvido de que la ciudadanía moderna es algo que han construido los sujetos mediante sus "acciones», ya sea mediante la insurrección en el caso de la Revolución Francesa o mediante la resistencia en de la Revolución estadounidense. Eventos políticos a los que nosotros les podemos añadir la rebelión neozapatista. Para dejar de ser súbditos se necesita de las acciones políticas, hace falta que los derechos sean conquistados mediante diferentes prácticas colectivas a las que da cauce la ciudadanía moderna.

\section{LA TENSIÓN ENTRE LIBERTAD E IGUALDAD}

En esta línea, Balibar defiende que el acceso y las prácticas ciudadanas estarán motivadas por lo que él denomina «la proposición de la igualibertad» que, como decíamos más arriba, parte de la suposición según la cual sin la libertad no habrá igualdad, al tiempo que sostiene que sin igualdad no puede haber libertad, lo cual a su juicio se puede probar de manera empírica. En sus propias palabras:

No hay ejemplos de restricción o de supresión de las libertades sin que se produzcan desigualdades sociales; ni desigualdades sin restricción o supresión de las libertades, incluso cuando se puede hablar de grados, tensiones secundarias, fases de equilibrio inestables, situaciones comprometidas en las cuales la explotación y la dominación no se distribuyen de manera homogénea sobre todos los individuos (Balibar, 1992: 137).

La ciudadanía pensada como una práctica dentro de la lógica de la igualibertad permite reivindicar de manera simultánea la igualdad y la libertad. La enunciación que se sitúa en el origen de la ciudadanía moderna (La Declaración) genera tensión en las relaciones entre los sujetos. Tensión que justifica la necesidad para la humanidad reconocida en la Declaración de avanzar en la profundización de la democracia. Sin embargo, esta tensión provoca que la ciudadanía sea siempre una 
ciudadanía imperfecta, en la medida en que sus rasgos generan una fuerza dialéctica sin fin, fuerza que sirve de guía democrática.

De esta manera, la ciudadanía moderna sólo podrá ser pensada como imperfecta, -lo que no quiere decir que sea una ciudadanía de segunda categoría- en la medida en que es interpretada como una ciudadanía en curso de refundación y resignificación permanente. Por ello, lo importante para Balibar no será la definición formal de la misma, sino que su centralidad para pensar la política pase por la construcción de las modalidades que garanticen el acceso a los derechos del mayor número de individuos (Caloz-Tschopp, 2004: 122).

Esta fuerza dialéctica de la igualibertad implica la imposibilidad de pensar una libertad civil que repose sobre privilegios y desigualdades o de instituir la igualdad de los hombres sobre el despotismo (Balibar, 1997: 21). Por ello, esta fuerza dialéctica que recubre la ciudadanía -en tanto que práctica dirigida por tal imposibilidad- es la que introduce en la misma su potencial emancipador y su fuerza transformadora.

Balibar establece una distinción según la cual la emancipación se centra en los sujetos, mientras que la transformación irá encaminada a las condiciones que determinan la política, entendiendo con ello que la igualdad afecta a los órdenes sociales y económicos, estando vinculada a la transformación, mientras que la libertad cuenta con un sentido jurídico-político relacionado con la emancipación (Balibar, 1994: 125).

A partir de esta distinción, Balibar reflexiona en torno a la ciudadanía como algo que está por llegar, como un mientras tanto. Lo que le interesa de la categoría -más que el estatus en sí, que se obtiene mediante el acceso a la misma- serán las prácticas para lograr el acceso mismo, en cuanto la ciudadanía, para él, no es una forma estable sino un proceso de adquisición mediante la praxis (Balibar, 2001: 211). La tensión de los procesos de emancipación y su viabilidad serán los motores que abran las posibilidades de la transformación, entendidas ambas, la emancipación y la transformación, como prácticas ciudadanas.

Este proceso de emancipación que defiende se fundamenta en lo que él denomina como la «autonomía de la política»: la política como fin en sí mismo. La emancipación así pensada sería un intento por definir la política atendiendo a la prioridad de la universalidad de los derechos. Lo que no puede ser pensado sino como un proceso interminable. Este proceso estará guiado por la dialéctica de la igualibertad, en la medida en que expresa el principio según el cual la colectividad no puede existir durante mucho tiempo si sus vínculos se encuentran fundados sobre el sometimiento de sus miembros a una autoridad natural y/o trascendente, o sobre la institución de la coerción y de la discriminación. Luego, para que se produzca el proceso de la autonomía de la política tienen que producirse, en principio, eventos tales como la Revolución Francesa, que desplacen los fundamentos del poder hacía elementos inmanentes, que se encuentran atravesados por la igualibertad, a saber, que se produzca un evento que «suprima la separación del pueblo consigo mismo» 
(Balibar, 1997: 21), lo que Rancière denomina momentos políticos ${ }^{7}$, los momentos en los que hay una dislocación entre los discursos dominantes y las demandas de los dominados y éstos dejan de obedecer y pasan a mandar.

Tales postulados tienen dos consecuencias. La primera vendría marcada por la nombrada unión del pueblo consigo mismo y supondrá la autodeterminación de éste, al abolir las restricciones de la libertad y de la igualdad que sean ilegítimas, lo que en último término supondrá la conquista de la democracia. Mientras que la segunda consecuencia es la que él denomina como "cláusula de reciprocidad», entendida como un derecho universal a la política y que explica de la siguiente manera:

Nadie puede ser liberado ni alzado a la igualdad -digamos emancipadopor una decisión exterior, unilateral, o por la gracia superior, sino solamente de manera recíproca, por un reconocimiento mutuo. [...] Los derechos que forman la igualibertad y la materializan son por definición derechos individuales, derechos de las personas. Éstos, no pudiendo ser acordados, deben ser conquistados y sólo se pueden conquistar de manera colectiva. Su esencia es el hecho de ser derechos que los individuos se confieren y se garantizan los unos a los otros (Balibar, 1997: 22).

Como vemos, la ciudadanía en cuanto práctica que estará siempre por venir, implica necesariamente una tensión promovida por la igualibertad que conduce hacia la emancipación. Sin embargo, la emancipación como horizonte hacia el que andar solo podrá alcanzarse (aunque como tal nunca se alcanzará, puesto que eso significaría el final de la política) de manera recíproca, a saber, reconociendo que sólo se puede ser libre si los otros lo son también y éste es el proceso que implica la autonomía de la política en relación con elementos trascendentes. El hecho de afirmar que no puede darse la autonomía de la política sino en los casos en los que los sujetos son los unos para los otros la fuente y la referencia última de la emancipación, supone que su fundamentación sea inmanente, la cual, repetimos, vendrá promovida por la igualibertad y su impulso sobre la universalidad de los derechos, lo que, en último término, sería transcendente.

\section{TRANSFORMACIÓN Y EMANCIPACIÓN}

La autonomía se vuelve política cuando una parte de la sociedad -él habla incluso de la humanidad-se encuentra excluida, ya sea de manera legal o no, del derecho universal de la política. Para profundizar en tales tesis trae a colación el concepto forjado por Jacques Rancière a partir de la teorización de Claude Lefort, de «la parte de los sin-partes». La " parte de los sin-partes» implica la imposibilidad de constituir el demos como una totalidad, como una simple distribución de sus partes ${ }^{8}$. Esta

\footnotetext{
${ }^{7}$ Sería las situaciones populistas propias de la filosofía de Ernesto Laclau.

${ }^{8}$ La visión de la política de Rancière se centra, al igual que en Balibar, en la persecución de la igualdad, de ahí que proponga: «reservar el nombre política a una actividad bien determinada [...] a esa que rompe la configuración de lo sensible donde se definen las partidas destinadas y las partes o su ausencia por una presuposición, según la cual quien no está definido no tiene plaza, es decir, esa de una parte de los sin-partes. Esta ruptura se
} 
«parte de los sin-parte» es la que abre la posibilidad de la ciudadanía, en cuanto ésta se vuelve su portavoz activa mediante las acciones encaminadas al acceso, al tiempo que supondría la facción susceptible de hacer valer la emancipación para los otros, debido a la cláusula de reciprocidad.

En esta línea sostiene que el combate de las minorías a lo largo de la historia por acceder a la ciudadanía es el combate por la emancipación de todos ${ }^{9}$. Por ello supone que esta historia no puede ser pensada como la historia de la reivindicación de derechos ignorados, como podía ser el caso de Will Kymlicka (2004) y su promoción de derechos a las minorías étnicas y nacionales, sino que es la lucha real por el disfrute de derechos ya declarados, en último término, por el acceso a la ciudadanía. Por todo ello, defiende la idea según la cual «el combate contra la negación de la ciudadanía es la vida de la política de la emancipación» (Balibar, 1997: 24). Combate central en la lucha neozapatista.

Sin embargo, la transformación, como decíamos más arriba, se vincula con las condiciones que determinan la política, de ahí que en lugar de hablar de una «autonomía de la política» en este caso hable de la «heteronomía de la política». Para dar cuenta de la transformación se refiere en primera instancia a la cita de Marx del 18 Brumario, según la cual los hombres hacen su historia, aunque no en las condiciones elegidas por ellos ${ }^{10}$. Como resulta obvio, no se transforma el mundo ex nihilo. En relación con la transformación de las condiciones que determinan la política, para Balibar, tal acción no se puede limitar a la simple transformación socioeconómica defendida por Marx, sino que se deberá ir más allá teniendo en cuenta las reflexiones de Foucault en torno al «biopoder» y la «biopolítica», las cuales introducen elementos impensados por Marx, en la medida en que no se limita a las condiciones materiales, sino que introduce las condiciones simbólicas y discursivas que subjetivan a los individuos.

manifiesta por una serie de actos que reconfiguran la definición del espacio o de las partes, de las partes y de las ausencias de partes. La actividad política es la que desplaza un cuerpo hacia el lugar de ser visto, de hacer escuchar algo como un discurso ahí donde sólo el ruido ocupaba el espacio; hacer escuchar como discurso lo que anteriormente era oído como ruido». (Rancière, $1995: 52-53$ ).

${ }^{9}$ A este respecto cita el combate de las mujeres, de los proletarios, así como a día de hoy el de las minorías sexuales o el de los sin papeles. En relación con estos últimos, y en torno a las manifestaciones y reivindicaciones que en las últimas décadas han llevado a cabo en el continente europeo, concretamente, en Francia, Balibar sostiene que ellos: «[...] han demostrado con sus acciones que el régimen de ilegalidad en el que se encuentra no tiene nada que ver con las reformas que sobre el mismo ha realizado el Estado, sino que al contrario, éste ha sido creado por el Estado mismo. [...] Por ello, nosotros les debemos que hayan recreado entre nosotros lo que es la ciudadanía, en tanto que no es ni una institución ni un estatus, sino una práctica colectiva». (Balibar, 2002: 24).

${ }^{10}$ La cita en cuestión es la siguiente: «Los hombres hacen su propia historia, aunque no la hacen de manera arbitraria en las condiciones elegidas por ellos mismos, sino en las condiciones dadas y heredadas del pasado» (Balibar, 1997: 26). 
Plantea la heteronomía de la política como la acción de remontar hasta las condiciones no políticas de la misma a partir de diferentes modelos, que en ciertos casos pueden parecer opuestos. Si Marx la piensa, como decíamos, desde la transformación del modelo socio-económico, para Balibar, habrá que introducir el modelo de producción del yo que toma de Foucault.

En lo que concierne a Marx, a juicio de Balibar, no se debe obviar el hecho de que las condiciones a transformar, en última instancia, son relaciones sociales que él identifica con las relaciones económicas, condiciones que a su vez tienen una historia y que por tanto son cambiantes, como muestra la historia del capitalismo. De ahí que de lo que se trate para Balibar, desde las tesis de Marx, será de romper con la lógica del cambio capitalista, de cambiar el cambio, de buscar la diferenciación con el cambio. Así las condiciones establecidas por el mismo sistema que tienden hacia la mundialización permitirán de manera efectiva la transformación del mundo. Este proceso también lo interpreta como si fuese un proceso sin fin, lo fundamenta en una dialéctica infinita (Balibar, 1997: 27, 29, 3839). La finalidad del proyecto neozapatista se ha ido definiendo de manera similar en contraposición al impulso al modelo neoliberal provocado por el Tratado de Libre Comercio de América del Norte.

Por otra parte, las condiciones en las que se centra a partir del pensamiento de Foucault son las que se refieren a los procesos de subjetivación. Tales procesos son los que convierten a los individuos en sujetos y los que los disponen para ciertas acciones. Son las tecnologías del yo. Tecnologías que se fundan en las relaciones de poder y que, como el mismo Foucault reconoce, incluyen la posibilidad de resistir (Foucault, 1994: 425) ${ }^{11}$. Por ello, se deberá comprender el proceso mediante el cual se han creado las subjetividades y los mecanismos de subjetivación. Y a partir de su compresión se podrán obstaculizar los dispositivos que inducen a los individuos a actuar de cierta manera y no de otra. Se trataría, por tanto, de comprender dichos procesos para desvelar los dispositivos que nos hacen ser como somos y poder liberarnos de ellos (Morey, 2014: 320). Y es en esta capacidad de resistir en la que Balibar barrunta la posibilidad de la transformación de las condiciones: a partir su estudio se podrán identificar las determinaciones que plantean, lo cual supondría la construcción o deconstrucción de la política.

Por tanto, el horizonte de la transformación que se vincula a la emancipación de los sujetos en su acceso a la ciudadanía, lo piensa desde la transformación del mundo en clave marxista, en términos de dialéctica de carácter infinito. De esta manera resulta inagotable. De ahí que alcanzarla será imposible. Al tiempo que deberá vincularse a los procesos de subjetivación de los individuos, lo que ya desde Foucault se encontraba abocado al pesimismo de la imposibilidad. Por ello, la propuesta de transformación de Balibar es planteada en forma de aporía, aunque

\footnotetext{
${ }^{11}$ Para Foucault no existen relaciones de poder sin resistencia a los poderes, de tal manera que la resistencia es inherente a las mismas, es más, se forma y se ejerce en el mismo lugar que las relaciones de poder, por lo que las técnicas de resistencia son, al igual que el poder, integrables en estrategias globales como las propuestas por Balibar (Foucault, 1994: 425).
} 
como aporía que invita a la creación permanente y a su confrontación con lo imposible (Balibar, 1997: 39).

\section{CIVILIDAD: RECONOCIMIENTO DEL OTRO Y DISENSO}

Los procesos de emancipación y de transformación son inviables o, mejor dicho, impensables para Balibar, si no se vincula la idea de ciudadanía que los contiene con la idea de civilidad. El concepto de «civilidad» lo trae a colación debido a su doble etimología. Para él supondría, por un lado, la traducción latina de politeia, en tanto que «institución o gobierno de una comunidad», al mismo tiempo que da cuenta de las costumbres (mœurs) públicas y privadas en el sentido hegeliano de Sittlichkeit. Así, el proceso de civilidad del que nos habla Balibar, inspirándose en el trabajo de Norbert Elías, aunque a diferencia de éste dándole un sentido eminentemente político, implica un proceso discursivo sobre las relaciones y las normas de comportamiento sociales tendentes a la construcción de valores morales, lo que supone el necesario reconocimiento del otro (Balibar, 1997: 45).

Así pensado, este proceso se asienta en la producción de las condiciones mismas de la acción política propias de la ciudadanía en lo que concierne al tiempo y al espacio $^{12}$. Condiciones que estarían encaminadas a reducir las formas de violencia extrema, como pueden ser la guerra o el terrorismo. Plantea, a este respecto, que la violencia extrema puede ser reducida a partir de la civilidad, en la medida en que ésta puede suavizar los conflictos, aunque no anularlos del todo. Es decir, si se toma la civilidad como una forma de reconocimiento en un territorio, en este caso los habitantes del planeta, que sin intentar anular las diferencias, aunque sí superar las discrepancias mediante la identificación de reglas comunes para la convivencia, se entiende por qué Balibar sostiene que la civilidad puede reducir la violencia sin anular del todo el conflicto (Balibar, 2010: 39-48). Dejar de pegar tiros en la selva, sin anular el disenso inherente a todas las comunidades humanas.

No piensa en una paz perpetua, sino en formas políticas ligadas al disenso, que pueden suavizar el antagonismo para que devenga agonismo, a nuestro juicio, en términos similares a los de Chantal Mouffe. No se trataría a la manera ultraliberal de pensar en un consenso que reduzca la política a la gestión de los recursos y a la supresión del disenso, sino de encontrar puntos en común que permitan a los adversarios políticos reconocerse en sus objetivos finales sin necesidad de exterminarse entre ellos, en cuanto éste será pensado como adversario con el que discutir y negociar.

La civilidad es una política que supone acciones y palabras, como freno a la violencia, contiene las expectativas de apertura, permanencia y recreación de un

\footnotetext{
${ }^{12}$ En la Conferencia dictada en la Universidad Paris Ouest el 24 de septiembre de 2010, en el marco del Sexto Congreso Internacional sobre Marx, titulada «Onze thèses sur Marx et le Marxisme», subrayó que el problema más acuciante de la política en la actualidad es la de la creación de espacios para la misma, frente a lo que argumentó que se deben construir espacios a partir de la civilidad que permitan, como veremos más adelante, no una ciudadanía nómada o un gobierno mundial federal, sino la comunicación de los movimientos locales.
} 
espacio público, en el que los sujetos puedan reconocerse y regular sus conflictos, valiéndose de los únicos medios de la civilidad, a saber, los enunciados, los signos y los roles. Estos medios estarán destinados a inventar prácticas de reconocimiento y de inclusión, en fin de cuentas, a realizar la emancipación y la transformación a partir de prácticas ciudadanas (Balibar, 2001: 182). De esta manera, defiende que el ejercicio de la ciudadanía resulta imposible sin el desarrollo de estas formas de civilidad en las relaciones sociales. A su vez, la civilidad deberá extenderse más allá del marco institucional de la ciudadanía como estatus. La civilidad en su vinculación con la ciudadanía también supondrá una práctica y no un mero estatus determinado en los códigos jurídicos. De una manera similar a la del «buen gobierno» neozapatista.

El hecho de que conciba la ciudadanía como una práctica y critique el constitucionalismo, no quiere decir, como se puede intuir en otros autores -como Giorgio Agamben o Antoni Negri-, que plantee la posibilidad de pensar una política a venir en términos de poder constituyente constante, o de estado de excepción permanente, puesto que para él «no hay ninguna sociedad (viable o vivible) sin instituciones ni contra-instituciones (con las opresiones que legitiman y las revueltas que promueven)»(Balibar, 2011: 47) ${ }^{13}$. Las acciones políticas de los ciudadanos a venir, ésas que incluirían a la «parte sin-parte», tendrán que realizarse por dos vías: la vía institucional y la extra-institucional, y a medida que se avance se deberán constituir las instituciones que necesite el poder constituido, aunque no de manera estática, sino dinámica e incluyente (Balibar, 2002: 175-204.).

\section{LA CIUDADANÍA «EN» EL MUNDO COMO HORIZONTE}

Esta problemática va al hilo de sus tesis en torno a las fronteras. Balibar defiende que cada libertad implica un cierto tipo de regulación, ya que de no ser así tal libertad implicaría sujeción. La supresión de las fronteras y la institución de un gobierno mundial con su correspondiente ciudadanía planetaria para él no serían deseables, en cuanto traerían consigo las particularidades más nefastas de la sociedad de control identificada por Deleuze: un monstruoso sistema mundial de observación de los movimientos individuales y de la vida. En el breve texto de Deleuze citado por Balibar (Deleuze, 1990: 240-247), primero nos habla, partiendo de la identificación realizada por Foucault de las sociedades disciplinarias, de cómo nos encontrábamos (el texto es de 1990) en un proceso hacia las sociedades de control, en las que la informática será capaz de elaborar un mecanismo que a cada instante indique la posición de cualquier cuerpo sobre el planeta.

De ahí que Balibar sobrentienda que tales mecanismos sin las fronteras, -con una ciudadanía totalmente desvinculada del territorio- podrían aplicarse sin más, dando las coordenadas de cualquier individuo en cualquier parte del planeta, lo que niega

\footnotetext{
${ }^{13}$ En una entrevista con Ernesto Laclau reconoce que en este punto acerca su teoría a la del argentino, es decir, en sus propias palabras: "Una de las cosas que Ernesto y yo tenemos en común es que no creemos que se deba elegir de una vez por todas para pensar la política si se está del lado de las instituciones o no». (G. Basterra, G. Glassson Deschaumes, R. Ivekovic, y F. Naishtat, 2010: 86-87).
} 
el derecho a inventarse a sí mismo y obliga a tener una identidad establecida y estable. Esto abriría las puertas a un posible gobierno mundial, que él entiende al igual que Arendt, como indeseable y sobre el que reposarían elementos peligrosamente antidemocráticos de vigilancia (Balibar, 2010: 335).

A pesar de sus reticencias a borrar definitivamente las fronteras, plantea un modelo en el que se mantengan -aunque con otro sentido al actual- a partir de lo que él denomina como «la democratización contractual de las fronteras». Esta democratización tendría por finalidad la de permitir una ciudadanía parcialmente independiente del territorio. Esta democratización contractual de las fronteras se funda en las relaciones de civilidad, y supone la creación de un espacio que, a su juicio, traduciría la división entre dos entidades, división que no podría ser impuesta, sino negociada desde el reconocimiento y es el reconocimiento lo que traduciría democráticamente la frontera (Balibar, 2010: 336).

Tal traducción del reconocimiento en las fronteras permitiría una ciudadanía a nivel cosmopolita. Balibar toma en consideración las reflexiones de Arendt en torno a la figura de los «sin Estado» y de los refugiados, de los apátridas, que él acerca a la «parte sin-parte», para pensar una forma de ciudadanía ${ }^{14}$. La forma de ciudadanía que piensa no sería una "ciudadanía mundial» en términos de circunscripción única, no piensa en un gobierno mundial o en una federación mundial, sino en una "ciudadanía en el mundo» entendida como "una cantidad cada vez mayor de prácticas y derechos cívicos en el mundo tal y como es, en el complejo sistema de espacios y movimientos que forman la realidad de lo que llamamos "mundo" para el que estamos tratando de crear espacios de civilidad» (Balibar, 2011: 28). Y a esta forma de ciudadanía la denomina «ciudadanía de la diáspora», la cual a nivel meramente local podría denominarse simplemente como «con-ciudadanía». Ambas permitirán imaginar una noción de ciudadanía como forma de reciprocidad de derechos y deberes entre los sedentarios y los nómadas (Balibar, 2010: 336-337) ${ }^{15}$.

De esta manera, plantea el horizonte de la ciudadanía como una práctica por la cual los ciudadanos y ciudadanas, devenidos con-ciudadanos y con-ciudadanas, sabiéndose sujetos a ciertas estructuras (institucionalizadas o no), reconociendo de manera recíproca el derecho a tener derechos de los otros, así como los impulsos de emancipación promovidos por la igualibertad, que promueven la inclusión de la «parte sin parte»-, encontrarán una meta hacia la que marchar sin nunca alcanzar,

\footnotetext{
${ }^{14}$ Esta figura también es retomada por Giorgio Agamben, aunque a diferencia de Balibar, él pensar desde la figura del apátrida descrita por Arendt, esto es, no pensarla como la parte de los sin parte, sino definitoria de nosotros mismos (Agamben, 2002: 25-37).

${ }^{15}$ En este sentido, frente a la definición de «ciudadanía nómada» de raigambre deleuziano, Balibar, prefiere la de «ciudadanía de la diáspora», en cuanto ésta última le parece más acertada debido a las definiciones de uso de ambos términos, análogos en algunas de sus acepciones. Si nos fijamos en tales, vemos que el hecho de ser nómada denota un lugar de origen al que se vuelve, es decir, da cuenta de rutas que se trazan en función de ciclos temporales, mientras que diáspora implicaría más bien el estado de dispersión de un pueblo. Ahora bien, el propio Balibar admite que se decanta por uno y no por el otro por convención.
} 
es decir, la posibilidad de una ciudadanía que estará siempre por llegar. Defiende la tesis de que la política, en el sentido de politeia, no ha sido del todo realizada, es más, ésta posiblemente es irrealizable, debido al desplazamiento incesante de las condiciones en las que se plantea el problema de la institución de la ciudadanía como práctica, como práctica, repetimos, que no tiene fin, pero que nos haría andar hacia un horizonte más democrático.

\section{LA NUEVA ESTRATEGIA NEOZAPATISTA}

El movimiento neozapatista, en su articulación con el resto del mundo, contiene a nuestro juicio varios de los rasgos de la propuesta del ciudadano-sujeto. Nuestro interés en el mismo se funda sobre todo en la articulación que pretende establecer con lo que ellos denominan «sociedad civil mundial» y en la cual nos parece que se puede identificar la tentativa de promover «una ciudadanía en el mundo» en términos próximos a la propuesta por el filósofo galo, que dentro de la conceptualidad neozapatista sería «un mundo donde quepan muchos mundos».

Los zapatistas de la Selva Lacandona cuentan con diferentes estructuras para tomar las decisiones que incluyen lo particular en la totalidad. Han generado instituciones de carácter dinámico que pretenden garantizar el axioma del mandar obedeciendo (Aguirre Rojas, 2008: 57). Este tipo de instituciones no estáticas, que en un primer momento se denominaron caracoles por plantear una forma de toma de decisiones en espiral, hacen converger las voluntades individuales con las colectivas, en cierta medida a la manera en la que Balibar plantea la figura del ciudadano-sujeto como un ciudadano que debe participar en la inclusión de más ciudadanos en pro de una sociedad más igualitaria y, por ende, más libre y justa.

El mandar obedeciendo sería una acción mediante la cual un individuo participa en el proceso de decisión colectiva por lo que queda sujeto de manera legítima a tal decisión. Este acercamiento de las tesis de Balibar con las prácticas neozapatistas, nos parece justificarse por el hecho de que éste último plantea una forma de ciudadanía en la que los individuos serían sujetos de la política que estarían sujetos a la política, esto es, el ciudadano mandaría como sujeto de la política y quedaría sujeto a dicha decisión a la que debería obedecer, lo que se vincula con la forma de la politeia incumplida a la que se refiere Balibar. Bien sabido es que ningún polités de la Grecia clásica adoptaría una decisión sin haber sido convencido antes por ella, al igual que los miembros neozapatistas. Ahora bien, estos últimos no pertenecerían a una aristocracia, sino que son la encarnación de la subalternidad que mediante sus acciones de resistencia han creado una forma de polis inclusiva, a la manera de «la parte de los-sin-parte» que realizan acciones para emanciparse ellos mismos, que combaten juntos contra la negación de su ciudadanía.

Así esta práctica incluiría, por un lado, la autonomía de la política encaminada a la inclusión de la pluralidad en la toma de decisiones, al mismo tiempo que estaría encauzada por instituciones de carácter dinámico en plena transformación permanente que buscan dar respuesta a las demandas de un cada vez mayor número de individuos $\mathrm{o}$, en términos zapatistas, de mundos. Esta forma de institucionalidad genera una forma de ciudadanía en términos de prácticas, en la cual la misma deviene un proceso y no una identidad fijada y estable que garantiza 
la inclusión de los márgenes en la toma de decisiones. Esta inclusión se acerca a la toma en consideración de la «parte de los sin-parte» en la articulación de un nosotros y en la profundización de la democracia propuesta por Balibar y que generan formas de subjetivación que reclaman, desde diferentes horizontes y con otras referencias, la vigencia del artículo de la Declaración.

Se puede afirmar que esa tensión se encuentra en la Constitución de los Estados Unidos Mexicanos, la cual reconoce, por otro lado, otro derecho en el que se puede inscribir la lucha neozapatista y que se conoce como el derecho a la insurgencia. Esto es, en su artículo 39 la Constitución mexicana reconoce que: "La soberanía nacional reside esencial y originariamente en el pueblo. Todo poder público dimana del pueblo y se instituye para beneficio de éste. El pueblo tiene en todo tiempo el inalienable derecho de alterar o modificar la forma de su gobierno». En cuanto la Constitución reconoce el derecho igualdad y a la libertad, en la misma línea que la Declaración a la que se refiere Balibar, no resulta descabellado pensar que el levantamiento de 1994 y sus reclamos desde entonces, que han obligado al Estado a modificar la Constitución para incluir las demandas de reconocimiento de los pueblos indígenas, sean una de las consecuencias de la tensión que genera la igualibertad y las luchas por el reconocimiento, al mismo tiempo que suponen un intento por hacer que las poblaciones indígenas accedan al derecho a tener derechos.

Así desde las subalternidades, los neozapatistas buscan articular un sujeto Ilamado Marco que vaya más allá de las fronteras de México y que ellos representan cuando enuncian que «es gay en San Francisco, negro en Sudáfrica, asiático en Europa, anarquista en España, palestino en Israel, indígena en las calles de San Cristóbal [...]». Dicha articulación de este ciudadano-sujeto pasa por las apelaciones:
A todos los individuos, grupos, colectivos, movimientos, organizaciones sociales, ciudadanas y políticas, a los sindicatos, las asociaciones de vecinos, cooperativas, todas las izquierdas habidas y por haber; organizaciones no gubernamentales, grupos de solidaridad con las luchas de los pueblos del mundo, bandas, tribus, intelectuales, indígenas, estudiantes, músicos, obreros, artistas, maestros, campesinos, grupos culturales, movimientos juveniles, medios de comunicación alternativa, ecologistas, colonos, lesbianas, homosexuales, feministas, pacifistas ${ }^{16}$.

Como vemos, se trata de construir un sujeto que busca una profundización democrática a partir de categorías transversales y pluralistas, cuyo papel sería el de incidir en la tensión que provoca la igualibertad mediante el reconocimiento de las diferencias y haciendo valer la tensión inherente a la Declaración, aunque desde otra perspectiva y que, por ende, escapa a las formas de subjetivación hegemónicas

\footnotetext{
16 «Primera Declaración de La Realidad» [disponible en línea: http://palabra.ezln.org.mx/ consultada el 3 de enero de 2017]. A su vez, el Comandante Marcos, tras unas declaraciones del Presidente mexicano, declara que «el Marcos es gay en San Francisco, negro en Sudáfrica, asiático en Europa, anarquista en España, palestino en Israel, indígena en las calles de San Cristóbal [...]».
} 
para generar otro tipo de proceso de identificación que se acerca a los procesos de los que nos habla Balibar.

A su vez, el proceso de la toma de decisiones se encuentra guiado por prácticas que recuerdan a la civilidad propuesta por Balibar. La civilidad como veíamos anteriormente era una praxis destinada a garantizar el reconocimiento incluyendo formas de disenso pacífico. Los catorce días del levantamiento zapatista y los veintitrés años restantes los podemos leer como un proceso de autonomización de la política, mediante acciones destinadas a reducir la violencia. El EZLN, en forma de aporía, plantea que ellos son «el ejército que se levantó para que no hubiesen más ejércitos» (Antón González, 2010). Sería un ejército que de manera pacífica pretende reducir la violencia sin que ello implique anular las diferencias, sino permitirles que se desarrollen gracias a la práctica de la civilidad implícita en la forma del mandar obedeciendo.

La práctica del mandar obedeciendo que se traduce por «aquí manda el pueblo y el gobierno obedece» sobre la que se constituyen las comunidades neozapatistas y que da cuenta de cómo desde una comunidad subalterna, que contaba con los derechos reconocidos por la Constitución de los Estados Unidos Mexicanos pero que no eran garantizados, da cuenta de ese paso señalado por Balibar que se produce tras el evento de la Revolución Francesa y de la Declaración, ya que con ella se trata de dejar de ser súbditos para ser ciudadanos sujetos a la participación política, a su tiempo, a su espacio y que pretenden ayudar a construir un mundo más justo, a saber, más igualitario y libre.

Por todas estas razones, entendemos que el proyecto neozapatista puede servir de modelo para pensar el ciudadano-sujeto, aunque también nos parece que el modelo del ciudadano-sujeto, nos puede servir para pensar las formas de la rebelión e institución neozapatistas desde la autonomía de la política. Ahora bien, como desde que el 27 de mayo de 2017 el Congreso Indígena de Gobierno decidió presentar una candadita con el apoyo de los neozapatistas, podemos decir que, a partir de ese momento, combinarán la heteronomía con la autonomía de la política.

María de Jesús Patricio Martínez, Marichuy, con su presencia en las elecciones presidenciales mexicanas representa una lucha por la integración de los marginados en el «derecho a tener derechos». Su programa se estructura a partir de siete principios que creemos que se acercan a los propuestos por Balibar. Los principios que ha enunciado al presentar su candidatura son a) el servir y no servirse, que podemos acercarlo al de reciprocidad del filósofo francés; b) construir y no destruir, que puede ser pensada como las formas de acción política y organizativas, c) obedecer y no mandar, lo que recuerda al sujeto a la política y de la política que constituyen al ciudadano-sujeto; d) proponer y no mandar como formas de civilidad; al igual que el de e) convencer y no vencer; f) bajar y no subir como forma de respeto de la iguallibertad y g) representar y no suplantar, en cuanto las luchas por la emancipación deben ser realizadas en busca de mayor libertad e igualdad para la ciudadanía en su conjunto.

Lo que se pretende con esta candidatura es que se cumplan los tratados de San Andrés en los cuales los indígenas del EZLN reclamaban simplemente ser mexicanos 
y que les sean respetados los derechos. A saber, que se les abra la puerta al derecho a tener derechos, desde una tensión similar a la que da sentido la Declaración y donde resulta una nueva forma de crear un mundo donde quepan muchos mundos.

De esta manera, nos encontramos con dos posturas que se rebelan contra la gobernanza como paradigma de la política y que piensan y actúan con una concepción de la política según la cual esta sería la actividad desde la que se crean mundos comunes.

\section{BiBLIOGRAFÍA}

AGAmBen, Giorgio (2002). Moyens sans fins. Notes sur la politique, Paris: PayotRivage.

AGUIRRE ROJAS, Carlos Antonio (2010). Les leçons politiques du néozapatisme mexicain. Commander en obéissant, Paris: L'Harmattan.

AlthUSSER, Louis (1996). Positions, Paris: Éditions sociales.

ANTÓN GONZÁLEZ, Eva (2010). "Las paradojas del movimiento zapatista», en Revista Paz y Conflicto. No. 3, 2010. Disponible en: http://redalyc.uaemex.mx/src/inicio/ArtPdfRed.jsp?iCve=205016387010 [consultado el 3 de septiembre del 2017].

ARENDT, Hannah (2002). La condition de l'homme moderne, Agora: Paris,

BALIBAR, Étienne (1992). Les frontières de la démocratie, Paris: La Découverte.

- (1997). La crainte de masses. Politique et philosophie avant et après Marx, Paris: Galilée.

- (2001). Nous, citoyens d'Europe ? Les frontières, l'État, le peuple, Paris: La Découverte.

— (2002). Droit de cité, Paris: PUF.

— (2010). La proposition de l'égaliberté. Essais politiques 1989-2009, Paris: PUF.

— (2010). «De l'extrême violence au problème de la civilité», Violence et civilité. Wellek Library Lectures et autres essais de philosophie politique, Paris: Galilée, pp. 39-48.

- (2011). Citoyen Sujet et autres essais d'anthropologie politique, Paris: PUF.

- (2012). "Los dilemas históricos de la democracia y su relevancia contemporánea para la ciudadanía», en Enrahonar. Quaderns de Filosofia, nº 48 , Servei de Publicacions Universitat Autònoma de Barcelona, Barcelona.

Basterra, Gabriela, Glasson Deschaumes, Ghislaine, IVeKOVIC, Rada, y NAISHTAT, Francisco (2010). «Entretien avec et entre Étienne Balibar et Ernesto Laclau» en Rue Descartes, $\mathrm{n}^{\circ} 67$, "Quel sujet politique?», Collège international de philosophie, París: PUF. 
BENSAÏD, DANIEL (2007). "Althusser et le mystère de la rencontre», consultado el 29 de enero de 2017, Marx au XXIe siècle: l'esprit et la lettre, en: http://www.marxau21.fr/index.php?option=com_content\&view=article\&id=86:alt husser-et-le-mystere-de-la-rencontre \&catid=29:althusser\&Itemid=55\#_ftn48

CALOZ-TSCHOPP, Marie-Claire (2004). Le devoir de la fidélité à l'État entre servitude, liberté, (in)égalité, Paris: L'Harmattan.

DeleuZe, Gilles (1990). Pourparlers 1972-1990, París: Les Éditions de Minuit.

ÉLIAS, Norbert (2011). El proceso de civilización, México: FCE.

FOUCAULT, Michel (1994). Dit et écrits III. (1976-1979), Paris: Gallimard.

MOuffe, Chantal (2014). Agonistique: Penser poliquement le monde, París: BeauxArts de Paris éditions.

NANCY, Jean-Luc (1989). "Après le sujet qui vient», Cahiers Confrontation, nº. 20, invierno-, Paris: Aubier-Montaigne.

MOREY, Miguel (2014). Escritos sobre Foucault, Madrid/México: Sexto Piso.

RANCIÈRE, Jacques (1995). La Mésentente. Politique et philosophie, Paris: Galilée. 